\title{
A Case of Late-onset Hyperinsulinemic Hypoglycemia: HNF4A Mutation
}

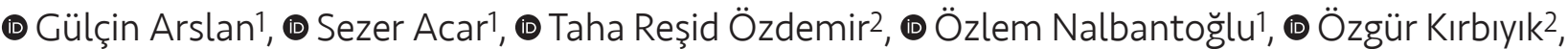 \\ [i] Özge Köprülü11, 圆 Beyhan Özkaya1, 固 Behzat Özkan1 \\ 1University of Health Sciences Turkey, Dr. Behçet Uz Child Disease and Pediatric Surgery Training and Research Hospital, Clinic of Pediatric \\ Endocrinology, İzmir, Turkey \\ 2University of Health Sciences Turkey, İzmir Tepecik Training and Research Hospital, Genetic Diagnostic Center, İzmir, Turkey
}

\begin{abstract}
Hyperinsulinemic hypoglycemia is a rare disease affecting infants and children. The frequency of HNF4A mutation is the third most common type following ABCC8 and KCNJ11 mutations. HNF4A inactivating mutations may cause hyperinsulinemic hypoglycemia generally in the neonatal period by impairing insulin production and the secretion in pancreatic $\beta$ cells. Herein, we present a case of an 8-month-old girl with hyperinsulinemic hypoglycemia who had normal birth weight. In this case, hypoglycemia became prominent after acute gastroenteritis and long-term glucose infusion was administrated to overcome hypoglycemia. On follow up, diazoxide treatment up to $12 \mathrm{mg} / \mathrm{kg} / \mathrm{day}$ was required to achieve normal glucose levels. In the molecular genetic analysis, a heterozygous mutation was found in the HNF4A gene (c.266G>A, p.R89Q), which was previously described in a case with MODY (maturity-onset diabetes of the young) type 1. During two weeks of hospitalization, while the glucose infusion rate was tapered, oral feeding was increased. Diazoxide treatment continued after discharge and was gradually stopped when she was at the age of 14 months. Afterwards, no hypoglycemia was observed. HNF4A gene mutation should be kept in mind even if there is no macrosomia or family history of diabetes in patients presenting with hypoglycemia and requiring diazoxide therapy.
\end{abstract}

Keywords: Hyperinsulinemic hypoglycemia, HNF4A gene, diazoxide therapy

\section{Introduction}

Hyperinsulinemic hypoglycemia $(\mathrm{HH})$ is a rare group of diseases that usually occur in infants and children. The incidence varies between $1 / 50,000$ and $1 / 2,500$ (1). Various prenatal, natal and postnatal factors can lead to this disease. Infants of diabetic mothers, macrosomia, perinatal stress (asphyxia, maternal toxemia, prematurity, IUGR), overgrowth syndromes (especially Beckwith-Wiedemann syndrome), blood transfusion/ exchange and misplaced umbilical venous catheters are associated with increased risk of $\mathrm{HH}(2)$. Other than these perinatal factors mentioned above, several genetic defects, which are mostly inherited autosomal recessive or dominant, have been identified as causes of hyperinsulinemia. Mutations in the $A B C C 8$ (ATP-binding cassette, sub-family C, member 8), KCN/11 (potassium inwardly rectifying channel, subfamily), member 11), GLUD1 (glutamate dehydrogenase), GCK (glucokinase) or HADH (hydroxyacyl-CoA dehydrogenase) are the most frequent causes leading to $\mathrm{HH}$ in infancy (3).

In addition, it has been shown that heterozygous inactivating mutations in the gene HNF4A (hepatocyte nuclear factor 4- $\alpha$ ), leading to maturity onset diabetes of the young (MODY) type 1 in adolescence and adulthood, 
may also cause $\mathrm{HH}$ in infants and children (4-6). HNF4A plays a role in insulin production and secretion by interacting with various transcription factors in pancreatic $\beta$-cells. It is not yet clear how HNF4A gene mutations cause hyperinsulinism in newborns. It is thought that it may be due to an abnormal expression of one or more target genes involved in insulin production and secretion in islet cells $(3,7)$. The frequency of HNF4A mutation in $\mathrm{HH}$ cases is reported to be approximately 5\% (8). Additionally, in some studies, it has been reported that HNF4A mutation was found to be the third most common cause after ABCC8/ $\mathrm{KCN} / 11$ mutations in patients with diazoxide-responsive $\mathrm{HH}$ $(8,9)$. The clinical findings in cases with HH due to HNF4A mutation frequently occur in the first week of life and are usually transient $(8,9)$. Moreover, in previous studies, it was reported that most cases with $\mathrm{HH}$ are macrosomic. In addition, in some of the cases, the disease can be controlled with glucose infusion alone; however, some patients may require diazoxide treatment.

In this report, unlike the cases that were reported to date, we present a case of an 8-month-old girl with normal birth weight who had $\mathrm{HH}$ due to HNF4A mutation requiring diazoxide therapy.

\section{Case Report}

An 8-month-old girl was brought to the emergency department with afebrile convulsion. It was learned that she had had vomiting and diarrhea for two days and her feeding had deteriorated. She was born with a weight of 3,130 g after an uneventful pregnancy and she did not have any health problems in the first eight months. Her parents have no consanguinity and there was no family history of diabetes or hypoglycemia. Physical examination revealed a weight of $7.5 \mathrm{~kg}$ (25-50 p), height of $68 \mathrm{~cm}$ (25-50 p), body temperature of $36.2^{\circ} \mathrm{C}$, heart rate of $122 / \mathrm{min}$, blood pressure of $92 / 60 \mathrm{mmHg}$ and capillary blood glucose of $37 \mathrm{mg} / \mathrm{dL}$. Her convulsion was due to hypoglycemia. Initially, she was unconscious and mildly dehydrated. The cardiovascular, respiratory, and gastrointestinal system examinations were normal. No findings regarding syndromic features were observed. On laboratory examination, venous blood glucose was $20 \mathrm{mg} / \mathrm{dL}$ and complete blood count, renal function tests, and ions were normal as shown in Table 1. Serum levels of lactate and ammonia were normal and urine ketone was negative. After receiving critical blood samples, $2 \mathrm{mg} / \mathrm{kg}$ of $10 \%$ dextrose was given intravenously. Consequently, the blood glucose increased to the normal range, and then 6 $\mathrm{mg} / \mathrm{kg} / \mathrm{min}$ of glucose infusion was continued. Even after the symptoms of diarrhea and vomiting improved and oral feed started, hypoglycemia ( $<50 \mathrm{mg} / \mathrm{dL}$ ) persisted. Later on, in order to overcome hypoglycemia, the intravenous glucose infusion rate was increased step by step to $8-10 \mathrm{mg} /$ $\mathrm{kg} / \mathrm{min}$. In order to rule out any neurological defect causing convulsion, EEG and cranial MRI of the patient were taken and both were reported as normal. While the increase in serum levels of cortisol and growth hormone were found to be normal during hypoglycemia, serum insulin was found to be relatively high (Table I). An increase of more than $30 \mathrm{mg} /$ $\mathrm{dL}$ in blood glucose was detected after the administration of $1 \mathrm{mg}$ of glucagon at the time of hypoglycemia, which is suggestive of $\mathrm{HH}$. Glucose infusion was increased up to 12 $\mathrm{mg} / \mathrm{kg} / \mathrm{min}$, but the clinical condition did not improve and normoglycemia was not achieved. Therefore, $5 \mathrm{mg} / \mathrm{kg} / \mathrm{day}$ diazoxide was started and gradually increased to $12 \mathrm{mg} / \mathrm{kg} /$ day. Subsequently, clinical improvement was achieved and the glucose infusion rate was tapered and stopped. Then, she was discharged with continued diazoxide treatment. On the outpatient follow-up, the dose of diazoxide was reduced and stopped at 14 months of age. No further hypoglycemia was observed during the treatment or post-treatment periods.

In the genetic analysis, while no mutation was found in $A B C C 8 / K C N J 11 ;$ a heterozygous missense mutation in the HNF4A gene (c.266G> A, p.R89Q) was seen. Her parents had no symptoms suggestive of diabetes, and their basal laboratory values (insulin, fasting glucose, HbA1c) were

Table I. Laboratory features of the patient at the time of hypoglycemia

\begin{tabular}{|l|l|l|}
\hline Parameter & Value & Normal range \\
\hline Glucose $(\mathrm{mg} / \mathrm{dL})$ & 20 & $60-100$ \\
\hline Blood urea nitrogen $(\mathrm{mg} / \mathrm{dL})$ & 10.1 & $5.1-12$ \\
\hline Creatinine $(\mathrm{mg} / \mathrm{dL})$ & 0.4 & $0.2-0.5$ \\
\hline Sodium $(\mathrm{mmol} / \mathrm{L})$ & 141 & $136-145$ \\
\hline Potassium $(\mathrm{mmol} / \mathrm{L})$ & 3.9 & $3.7-5.5$ \\
\hline Hemoglobin $(\mathrm{gr} / \mathrm{dL})$ & 11.9 & $12-16$ \\
\hline Leukocyte $\left(\mathrm{cells} / \mathrm{mm}^{3}\right)$ & 6,100 & $5,000-15,000$ \\
\hline Platelets $\left.(\mathrm{cells} / \mathrm{mm})^{3}\right)$ & 305,000 & $150,000-450,000$ \\
\hline C-reactive protein $(\mathrm{mg} / \mathrm{dL})$ & 0.02 & $<0.5$ \\
\hline Serum insulin $(\mu \mathrm{U} / \mathrm{mL})$ & 4.4 & $2.6-24.9$ \\
\hline C-peptide $(\mathrm{ng} / \mathrm{mL})$ & 0.825 & $0.9-7.1$ \\
\hline Growth hormone $(\mathrm{ng} / \mathrm{mL})$ & 8.8 & $<8$ \\
\hline Cortisol $(\mu \mathrm{g} / \mathrm{dL})$ & 18.9 & $3.7-19.4$ \\
\hline Ammonia $(\mu \mathrm{gg} / \mathrm{dL})$ & 73 & $27-115$ \\
\hline Lactate $(\mathrm{mmol} / \mathrm{L})$ & 14 & $4.5-19.8$ \\
\hline
\end{tabular}


normal. However, since they did not accept, genetic analysis could not be performed. Informed consent was obtained from the parents of the patient for this study.

\section{Discussion}

Herein, we present an 8-month-old girl with $\mathrm{HH}$ due to heterozygous missense mutation in the HNF4A gene (c.266G> A, p.R89Q) that was previously reported to be pathogenic in a patient with MODY (10). The clinical features of hypoglycemia in patients with a HNF4A gene mutation have a wide clinical spectrum ranging from a mild clinic, which was improved by feeding regulation alone, to severe hypoglycemia that requires diazoxide therapy for many years. It is not yet clear how HNF4A gene mutations cause $\mathrm{HH}$. However, HNF4A is known to play a key role in the interaction of some transcriptional factors in islet cells $(11,12)$. In addition, it has been shown that HNF4A is associated with PPAR $\alpha$ (peroxisome proliferator-activated receptor alpha), a transcription factor that controls the gene expression of some enzymes involved in $\beta$-oxidation of fatty acids (13).

No genotype-phenotype relationship was shown in patients with $\mathrm{HH}$ due to HNF4A mutations. However, it is suggested that macrosomia and $\mathrm{HH}$ are more frequent especially in mutations in the promoter region (P2) of the gene (5). The mutation in our case (c.266G> A, p.R89Q) is located in the second exon outside the $\mathrm{P} 2$ region. In addition, there are numerous mutations outside this region that have been shown to cause $\mathrm{HH}$ (4). Finally, further studies are needed to demonstrate this relationship.

$\mathrm{HH}$ that was caused by HNF4A gene mutations was first described by Pearson et al. (4). In the same retrospective study of families with HNF4A mutation-associated diabetes, it was reported that $\mathrm{HH}$ due to a heterozygous HNF4A mutation was seen in 8 out of 54 infants. Flanagan et al. (8) detected a genetic mutation in 59 of 220 diazoxideresponsive $\mathrm{HH}$ cases and that 11 (5\%) were HNF4A mutations, 4 of these were de novo. In a study conducted by Kapoor et al. (9), HNF4A mutation was detected in 7 out of 41 patients with diazoxide-responsive $\mathrm{HH}$.

$\mathrm{HH}$ cases with a HNF4A mutation are usually born with macrosomia (4). In a retrospective study by Pearson et al. (4), 56\% of cases were reported to be macrosomic (790 gr more than controls). In another study, it was reported that the mean birth weight of patients with a HNF4A mutation was 751 gr more than those of healthy controls (6). In the study by Flanagan et al. (8), 9 of 11 patients were found to be macrosomic. In addition, in some case reports, macrosomic cases with a HNF4A mutation have also been reported $(5,14)$. In contrast, our case had a normal birth weight of 3,130 g, suggesting clinical variability.

$\mathrm{HH}$ due to HNF4A mutations usually present in the neonatal period $(5,8,9)$. In the study by Flanagan et al. (8) all patients with HNF4A mutations presented with hypoglycemia in the first week of life (median age 1 day, range 1-7 days). In a study conducted by Pearson et al. (4), hypoglycemia was observed in the neonatal period in all cases with $\mathrm{HH}$ due to HNF4A mutation. In another study, it was reported that patients with HNF4A mutations presented with hypoglycemia earlier than those with ABCC8/KCNJ11 mutations in the neonatal period (9). At the same time, apart from the neonatal period, $\mathrm{HH}$ due to HNF4A mutation that presented in childhood (at the age of 2.5 years) were also reported, suggesting that phenotypes in HNF4A may be heterogeneous with variable age of onset (15). In line with this, in our patient who had a missense mutation in the second exon of HNF4A, HH was detected in a late period (at the age of 8 months) with no previous symptoms or hospital admissions regarding hypoglycemia. Moreover, hypoglycemia was not reported in another patient with the same mutation as our patient and that case only presented with diabetes at the age of 25 years, which is suggestive that even in cases with the same mutation, different clinical presentations may occur (10). Moreover, besides the impact of a HNF4A mutation, gastroenteritis in our patient may also have precipitated the development of the clinical manifestations of hypoglycemia.

$\mathrm{HH}$ in patients with HNF4A mutations is usually transient $(4,5)$. Some cases require short-term glucose infusion to normalize glucose levels, and others need diazoxide treatment. In the study by Kapoor et al. (5), 3 infants with severe $\mathrm{HH}$ were treated with diazoxide over periods ranging from 8 to 18 months and moreover, one of these cases was treated up to the age of 32 months. In our case, who was admitted with hypoglycemia at the age of 8 months, we used diazoxide treatment for 6 months and following discontinuation of the drug, euglycemic state was achieved.

HNF4A mutations, which may lead to hypoglycemia in the neonatal period, can also cause MODY type 1 in adolescents and adults. Therefore, a history of diabetes in a family member is of great importance in cases with $\mathrm{HH}$, as it allows us to consider HNF4A mutations in the differential diagnosis $(1,5)$. However, in $\mathrm{HH}$ cases without any family history of diabetes, the possibility of a mutation in HNF4A should not be excluded as it may be caused by de novo 
mutations $(7,14)$. In one study, only 4 of the 11 cases with a HNF4A mutation had a family history of diabetes, and the remaining did not have a family history of diabetes (8). Our patient did not have a family history of diabetes and genetic analysis of her parents revealed no mutation in the HNF4A, suggesting de novo mutation should be considered.

It is known that cases with a HNF4A mutation developed MODY type 1 in the later period (usually in adolescence or adulthood) after the regression of hypoglycemia (14). Five out of 54 patients with a HNF4A mutation were reported to have developed diabetes during adolescence (8). The age of onset of diabetes is variable in these patients. This has been shown to be related to the type and position of the mutations (15). It has been suggested that HNF4A mutations affecting exons 9 and 10 are associated with a later onset of diabetes compared to those with mutations in exons 2-8 (15). However, the case who had the same mutation as our patient presented with diabetes at the age of 25 years old, which is inconsistent with previous study results. We can speculate that there is no clear relation between genotype and phenotype. These findings point to the fact that in patients with HNF4A mutations, there is variability in the time of emergence of diabetes as well as the onset of hypoglycemia. Therefore, we should carefully follow-up those patients with $\mathrm{HH}$, who have missense mutation in the $2^{\text {nd }}$ exon of the HNF4A, in terms of developing diabetes in later life.

\section{Conclusion}

In conclusion, hyperinsulinism should be considered in infants who present with hypoglycemia even after the neonatal period. Clinical features of $\mathrm{HH}$ caused by HNF4A mutations can be varied in terms of age of onset, longevity and severity of hypoglycemia. Moreover, HNF4A gene mutation should be kept in mind in patients presenting with hypoglycemia and requiring diazoxide therapy even if there is no macrosomia or family history. Additionally, it should be kept in mind that $\mathrm{HH}$ cases with HNF4A mutations have a risk of developing diabetes in later in life and, therefore, these cases should be followed at regular intervals.

\section{Ethics}

Informed Consent: Informed consent was obtained from the parents of the patient for this study.

Peer-review: Externally peer-reviewed.

\section{Authorship Contributions}

Concept: G.A., B.Özkan., Design: G.A., S.A., Data Collection or Processing: S.A, T.R.Ö, Ö.K., Ö.Kö., Analysis or
Interpretation: Ö.K., B.Ö., Ö.N., Literature Search: G.A., S.A., Writing: G.A., S.A.

Conflict of Interest: No conflict of interest was declared by the authors.

Financial Disclosure: The authors declared that this study received no financial support.

\section{References}

1. Huerta-Saenz L, Saunders C, Yan Y. Challenging diagnosis of congenital hyperinsulinism in two infants of diabetic mothers with rare pathogenic KCNJ11 and HNF4A gene variants. Int I Pediatr Endocrinol 2018;2018:5.

2. Palladino AA, Bennett MJ, Stanley CA. Hyperinsulinism in infancy and childhood: when an insulin level is not always enough. Ann Biol Clin (Paris) 2009;67:245-54.

3. Kapoor RR, Flanagan SE, James C, Shield J, Ellard S, Hussain K. Hyperinsulinaemic hypoglycaemia. Arch Dis Child 2009;94:4507.

4. Pearson ER, Boj SF, Steele AM, et al. Macrosomia and hyperinsulinaemic hypoglycaemia in patients with heterozygous mutations in the HNF4A gene. PLoS Med 2007;4:e118.

5. Kapoor RR, Locke J, Colclough K, et al. Persistent hyperinsulinaemic hypoglycaemia and maturity-onset diabetes of the young due to heterozygous HNF4A mutations. Diabetes 2008;57:1659-63.

6. Fajans SS, Bell GI. Macrosomia and neonatal hypoglycaemia in RW pedigree subjects with a mutation (Q268X) in the gene encoding hepatocyte nuclear factor4alpha (HNF4A). Diabetologia 2007;50:2600-1.

7. Kapoor RR, Heslegrave A, Hussain K. Congenital hyperinsulinism due to mutations in HNF4A and HADH. Rev Endocr Metab Disord 2010;11:185-91.

8. Flanagan SE, Kapoor RR, Mali G, et al. Diazoxide-responsive hyperinsulinaemic hypoglycaemia caused by HNF4A gene mutations. Eur J Endocrinol 2010;162:987-92.

9. Kapoor RR, Flanagan SE, Arya VB, Shield JP, Ellard S, Hussain K. Clinical and molecular characterisation of 300 patients with congenital hyperinsulinism. Eur / Endocrinol 2013;168:557-64.

10. Johansson S, Irgens H, Chudasama KK, et al. Exom Sequencing and Genetic Testing for MODY. PLoS ONE 2012;7:e38050.

11. Boj SF, Parrizas M, Maestro MA, Ferrer I. A transcription factor regulatory circuit in differentiated pancreatic cells. Proc Natl Acad Sci U S A 2001;98:14481-6.

12. Odom DT, Zizlsperger N, Gordon DB, et al. Control of pancreas and liver gene expression by HNF transcription factors. Science 2004;303:1378-81.

13. Gupta RK, Vatamaniuk MZ, Lee CS, et al. The MODY1 gene HNF4alpha regulates selected genes involved in insulin secretion. I Clin Invest 2005;115:1006-15.

14. Arya VB, Rahman S, Senniappan S, Flanagan SE, Ellard S, Hussain K. HNF4A mutation: switch from hyperinsulinaemic hypoglycaemia to maturity-onset diabetes of the young, and incretin response. Diabet Med 2014;31:e11-5.

15. Tung $/ Y$, Boodhansingh $K$, Stanley CA, De León DD. Clinical heterogeneity of hyperinsulinism due to HNF1A and HNF4A mutations. Pediatr Diabetes 2018;19:910-6. 